\title{
Media Literacy and Media Education: How to Master a New Paradigm of Civilization
}

\author{
Bozena Supsakova \\ Comenius University, Faculty of Education, Bratislava, Slovakia
}

\begin{abstract}
We are witnessing a new dimension of the Internet development. The question is, at what age and to what extent children are capable to acquire basic communication skills Internet era. This paper considers the issue of media literacy and media education as a way to education of the young generation and a better understanding of media content. The article describes a new paradigm New Millennium - New Media - New Forms of Personal and Mass Communication as reflected in the behavioural patterns of the current young generation, including a survey of perception and use of the Internet by children in Slovakia. Particular attention is paid to media education and media literacy in some European countries. As for our research, we aimed at the study of nowadays communication tools and behaviour in the online environment younger school age (8-10) in Slovakia. The research was implemented on the sample of 1452 children. Not surprisingly, that children younger school age have the basic digital skills and are able to communicate in virtual space. The three most important things without which all the pupils not imagine their lives are in this order: TV, internet and mobile. Quite surprising is the finding that younger school age children are familiar with social networking and their active use every fourth schoolboy! In personal communication with friends we discovered new phenomenon in this age group - a virtual meeting.
\end{abstract}

\section{Introduction}

As soon as in the twenties of the 20th century mass communication is becoming a global phenomenon helping to form the face of the current global environment. Images and sounds have become the basic elements of the mass media reality, which since has been forming the social and political landscape of the modern society [2]. More than fifty years ago, Marshall McLuhan, well described by history as a prophet and magician of the electronic age and the electronic revolution, argued that "every new technology is simply an evolutionary and biological mutation, which opens up new doors of perception and new fields of behaviour for mankind"“[8].

\section{New Forms of Personal and Mass Communication}

The current civilization paradigm can be characterized: New Millennium - New Media - New Forms of Personal and Mass Communication. The Internet, a new phenomenon of the global information infrastructure and access to information, was born in the seventies of the last century and began to affect significantly the way we communicate, collect and share information. Nowadays, it penetrated to new dimensions of its development, as developing multimedia technologies and content (Web 2.0), as well as new phenomenal contacts: mobile communications (mobile phones, smart phones, tablets) and social networks (Facebook, Twitter and a lot of others). The Internet is used nowadays worldwide by one third of people, we register incredible five billion subscribers to mobile services; in economically developed countries one user has more than one prepaid mobile service [11]. This modern paradigm obviously affected and influenced also the younger generation.

It is clear that the time that has come requires to learn new literacy - media literacy, but also to gain or acquire new social skills, especially how to orient, and most recently, to self-realize in the multimedia on-line space. This is a series of new communications competences and skills that include the ability to search, select, analyse, evaluate, create, and thus to pass information in variety of formats by word, image, sound. Recently, it includes also with the integration of all these elements - it means the multimedia integration.

Media literacy is defined by most policymakers and academics as the ability to "access, analyse, and evaluate media" in multiple forms and "communicate competently" within these forms [6] [10]. Traditionally, education, training and lifelong learning policies have been perceived as critical to developing media literacy. Therefore, any future interventions in this area must take into account that 
media messages are constructed, have a purpose, may be affected by potential biases, and are subject to regulatory issues that potentially affect access and use [7] [9].

At the theoretical level, media literacy can therefore be characterized as an ability to seek, receive, analyse, evaluate and communicate a (multi)media content. By M. Hoechsmann and S. Poyntz "media literacy is a summary of competences that allow us to interpret the media content and processes of the media world to create our own media, to recognize and deal with the social and political impact of media in everyday life" [3]. While the media content (news, music, web sites) are produced by broadcasters, film-makers, web designers, and are mediated by media technologies (television, film, digital technologies such as smart phones, mp3 players, tablets or digital cameras). An interesting view on media literacy was expressed by a prominent expert and author of Media Literacy, W. J. Potter, who says that "to become more media literate means a boundary between your real world and the world, produced by media. Being media literate also means getting the information and experience you want, without having to get out of the media what you do not want. Then you will be able to create your life as you want, and do not allow the media to create it as they want - on your behalf" [11]. The author clearly comes up to the contemporary world of media, which continues its unprecedented development and is beyond the power of human senses to cover all new information created every day. Bearing in mind that every day in the world 1500 new titles of books are published, radio stations broadcast 65.5 million hours of the original program per year, televisions 48 million hours. At present, 35 million websites are available, Internet users send 300 billion emails per day, on YouTube 50 thousand hours of new videos are added daily, and in the short messaging social network known as Twitter, 70 million twitties a day are sent. People spend with new media more and more time, on average it is 8 hours a day - all studies over the past three decades confirm that. Children (and young people) in Slovakia are not an exception.

Within the past decade, policymakers have recognized the importance of critical approaches to media messages, prompting position statements, exploratory research, and policy recommendations.

\section{1. The European approach to media literacy}

In particular, the competencies correspond with the definitions of media literacy developed by members of the Media Literacy Expert Group convened by the European Commission as the ability to access, analyse, and evaluate the power of images, sounds, and messages which we are now being confronted with on a daily basis and are an important part of our contemporary culture, as well as to communicate competently in media available on a personal basis. Media literacy relates to all media, including television and film, radio and recorded music, print media, the Internet, and other new digital communication technologies.

The aim of media literacy is to increase awareness of many forms of media messages encountered in our everyday lives. It should help citizens to recognize how the media filter their perceptions and beliefs, shape popular culture and influence personal choices. It should empower them with critical thinking and creative problem-solving skills to make them judicious consumers and producers of information. Media education is part of the basic right of every citizen, in every country in the world, to freedom of expression and the right to information and it is instrumental in building and sustaining democracy.

Media literacy may be defined as the ability to access, analyse, and evaluate the power of images, sounds, and messages which we are now being confronted with on a daily basis and are an important part of our contemporary culture, as well as to communicate competently in media available on a personal basis. Media literacy relates to all media, including television and film, radio and recorded music, print media, the Internet and other new digital communication technologies.

Media literacy is often summarized as the capacity of individuals to interpret analyses, contextualize, and produce media messages. Any convergence of multiple platforms and technologies in which a variety of languages and media streams co-exists and merges the concept of media literacy affords an inclusive and practical point of reference. In this regard, media literacy implies a broadening, but also a reinforcement of the elemental functions, whereby, traditional literacy is defined, i.e., a critical and analytical reading of numerous simultaneous sources of information, reasoning, influenced by social injunction, symbolic and cultural codes and conventions. With the development of the digital world, the ways to transfer knowledge have shifted from the traditional media (television, radio, books, newspaper, and cinema) and have become increasingly dependent on digital technologies (Internet). While not undermining the relevance of the traditional media sources, nowadays, possessing certain technical skills to access digital technologies without difficulties enables citizens to engage more with and participate in every level of public life, 
from social networking to e-government. Individuals not equipped to utilize digital technologies are necessarily isolated from this aspect of the media flow, next to the additional negative effects of being solely reliant on traditional media to obtain information (Testing and Refining Criteria to Assess Media Literacy Levels in Europe, 2011, p. 14).

The European approach to media literacy covering all media and media literacy levels includes [14]:

1. Feeling of comfort when using all existing media from newspapers to virtual communities;

2. Active use of media through interactive television, use of Internet search engines or participation in virtual communities and better exploiting of the potential of media for entertainment, cultural and inter-cultural dialogues, learning and everyday applications (e.g. libraries, webcast and podcast services);

3. Critical approach to media in terms of quality and accuracy of their content (e.g. the ability to evaluate information, (prudent) perception of advertising in various media, smart use of search engines);

4. Creative exploiting of media, since the evolution of media technologies and the growing importance of the Internet as a distribution channel allow the growing number of Europeans to create and disseminate images, information and content;

5. Understanding of economic relations in the media industry and the difference between pluralism and media ownership, awareness of copyright issues, which is needed for so-called culture of legality, especially for the younger generation in its double position as consumers and content producers.

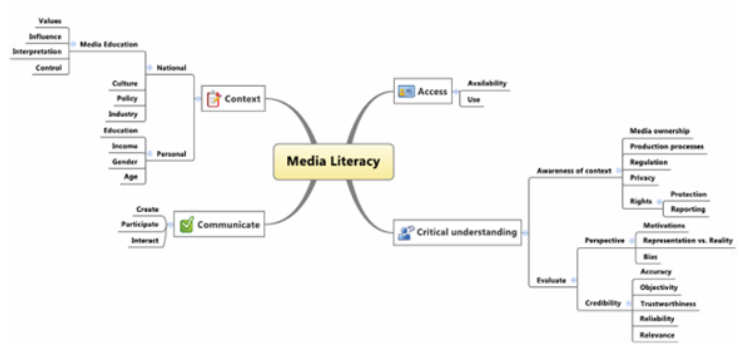

Figure 1: Commonly recognized aspects of media literacy (Testing and Refining Criteria to Assess Media Literacy Levels in Europe, 2011)

\section{The media reality is not always an ,actual "reality}

Information society delivers almost uncontrolled growth of media messages. To some extent, this new functionality was brought with new social networks and media that allow anyone to create any content, and publish it publicly and globally. The public space thus offers countless sources of information, which is increasingly difficult to orient in and to verify its validity and relevance. The media reality is not always an ,actual "reality, the boundaries between „true“ and „false“ are vague and often fictitious. This virtual world is naturally attractive, especially for children (and youth) and the part of the population is among the first to be able to acquire new skills quickly and thus to obtain gradually a new - media - literacy.

Young people crave much more frequently than adults to control new technologies and know to manage them very easily while their cognitive skills and the ability to make decisions based on values are not yet fully developed. Globalization and convergence of media, along with a wide range of options they offer arouse also new concerns: flood of information; uniformity undoubtedly caused by the dominance of one language and one culture in the new media, the increasing commercialization. There is also a serious risk of a new form of social exclusion for those who cannot communicate through the media and/or are unable to assess their content critically.

\section{Children read only 80 minutes daily, but spent four times more watching a screen}

Our research adds that in Slovakia "children $8-10$ years old spend about 5 hours watching a screen. Daily they read only for 1 hour and 20 minutes, while $87 \%$ of them focus mostly on the text and $13 \%$ on images (illustration), 11 to 14 year old children 7 hours daily watch TV and read daily 1 hour, while $78 \%$ of them focus on the text and $22 \%$ on images (illustration)" [17]. In frame of the another project in Slovakia, an on-line survey panel of active Internet users, confirmed that the most frequently used activities with mobile phones carried out by children include making calls, sending SMS or MMS messages, taking photographs, listening to music or radio and playing games. The survey results indicate that children of parents, who themselves actively use the Internet, spend too much time on-line and the most frequently is the Internet used by the eldest children, i.e. of 16-19 years of age, daily (76\%) or 
several times a week (20\%). The most common activities of youth (16-19 years) on the Internet are searching for information (89\%), chatting (88\%), emails $(79 \%)$, and downloading of music, pictures and movies $(76 \%)$. Youngest children (6-9 years) spend most of the time playing on-line games, and most of all seeking entertainment and information, contacts of their family and friends, as well as contacts for new friends. Provision of data through the Internet is risky, particularly in the age group from 10 to 19 years. The most common information provided through the Internet includes email address, photo, phone number and home address [12]. Regarding the threats and risks on the Internet "more than a quarter of interviewed children are aware of being in a risky situation sometimes. The younger children, the more often they state having met risks. It could be related to a raising awareness of Internet risks as well as that a lot of activities on the Internet is done by still younger children when they are not able to handle difficult situations (this age shift has been a long-term trend). Children aged 9-10 have got less technical skills and experiences with social situations. They have not got developed their abstract and critical thinking sufficiently yet and are not able to consider consequences of their actions properly, what are significant disadvantages in decision making in ambiguous situations" [26]

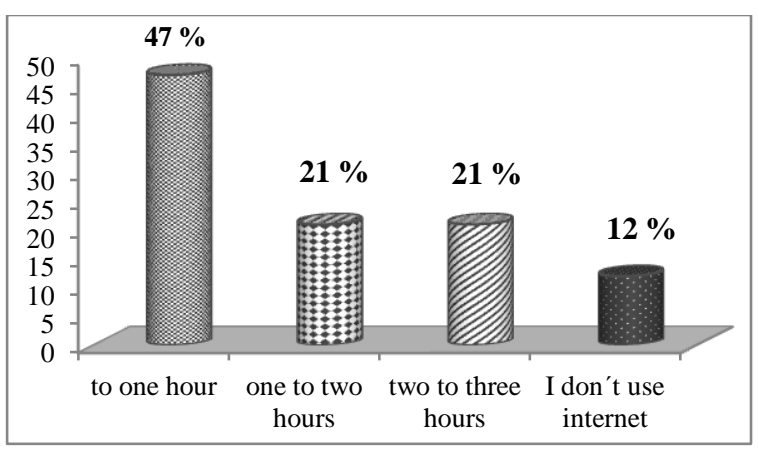

Figure 2. How much time do you spend on the Internet (A survey among children younger school age 8-10 years in Slovakia, 2010, N = 301). Source: Šupšaková (2010).

Research of D. F. Roberts and U.G. Foehr shows that at average a child and young person ( 8 - 18 years) spend in the new media ecosystem up to 7 hours 50 minutes a day, and the new trend is to use multiple functions and resources at the same time (so called multitasking - performance of several activities at once), when e.g. a young man is listening to music on the Internet, at the same time chatting with friends and in another window on the screen watching video [15]. It is not surprising that this generation of children and teenagers acquires the name „M generation", i.e. a generation strongly linked with media [11]. We can definitely say that if in the past media literacy was linked mostly with written words, now it is not valid, as new types of literacy enter our lives -visual literacy, computer literacy, context (content) literacy.

\section{Media education and curriculum}

Media education creates a space for young people to express free and the right to information. It is beneficial not only for their personal development, but it enhances participation and interactivity in society. Thus it prepares them for democratic citizenship and political consciousness. As pointed out also in studies of Buckingham, education for media literacy is ,,a potentially very significant place to define future civic attitudes of individuals, especially in the ability to combine basic procedures in the field of gathering and analysing of media messages with civic participation and social action"[1]. As he further notes, ,the media education curriculum must socialize young people, to acquire experiences from social changes"[1]. We can also agree with the Thomans and Jolly who say that education can "begin in the classroom, but culminates in a meaningful, creative participation of individuals in a broader cultural and social environment, and leads to personal and political transformation from a passive observer of events to an actionable citizen who can take interested citizen attitudes" [25] .

Media education is here to help children to cultivate their curiosity to learn how to assess various issues and situations in contexts and in a complex, to accept diverse perspectives and think optimistically to the future. Reflected into the educational practice, media education at the primary level of education should include all personal levels of children/students as well as cognitive (basic orientation in the media environment, recognizing of differences and diversity, decoding of reality represented by media, understanding the positive and negative impacts of the media, etc.), psychomotoric (active communication in the media environment, creation of their own media content, ability to collaborate and communicate with the media environment), and attitudinal (the ability to take their own attitude to media products, the ability of critical analysis, responsibility for content creation, etc.). Also in this case it would be valid that the practice is the criterion of truth. The media environment should become a textbook as well as a kind of laboratory of media education in schools. 


\section{1. Approach of European countries}

At present, the media education is included into the content of education in most European countries, where it is mostly integrated into the compulsory subjects, particularly into their mother language subject, communication education as an interdisciplinary subject, sociology, psychology, art history, and so on. In some countries, it is also part of non-formal education.

In the UK, it is a part of the English language, while its main task is to teach children/students to develop critical opinions to media texts and institutions. In France, since 2006, media education has been included in the areas of education, which mainly deals with social and civic issues. On the other hand, Belgium integrated media education into their music education or foreign languages.

Germany experienced the biggest boom in the sixties and seventies of the last century, media education is today a part of the compulsory subjects (German, aesthetic or artistic education, music, and social science). In Finland, it is integrated into the (interdisciplinary) subject-communication education, in recent years, however, more and more high schools offer media education in special courses. Sweden, Denmark, and Austria develop media competencies in the frame of other compulsory subjects. In Hungary, film and media education were included in the curricular documents already in 2003 as a part of other compulsory subjects.

In the Czech Republic, already in 2002, an educational and simultaneously pilot Media Smart Project had been initiated whose objective was to increase a media literacy of primary school students at the age of 6-11 years. Based on the recommendation of the Ministry of Education, Youth and Sports of the Czech Republic from 2008/2009 pupils in elementary and secondary schools can attend courses of media education, if their school included it into their educational programs. Based on recommendation of the Ministry of Education of Youth and Sports of the Czech Republic from $2008 / 2009$, the students of elementary and secondary schools are able to attend media education lessons if the school included such form of education into its educational programs. According to conceptual framework educational program of the Ministry of Education of Youth and Sports of the Czech Republic, the media education is - in addition to personal and social education, education for democratic citizen, education towards thinking within European and global relations, a multicultural education and environmental education- being integrated into education as a cross-cutting topic.
Media education in such a form has become a mandatory part of school education programs in elementary schools and high schools.

\section{2. Media education in Slovak republic}

Institutional and formal framework of media education in Slovak republic is created with the Concept of media education in the Slovak Republic in the context of lifelong learning, which characterizes and describes formal and informal forms of education. (The Concept was preceded by experimental verification of media education).

The Concept was preceded by experimental verification of media education as a voluntary and optional subject in 5th - 9th class of primary schools and 1 st to 4 th class of eight-year grammar schools. Each class had other core media to teach, in the fifth year, it was television, in the sixth film, in the seventh auditory media, in the eighth printed media and in the ninth class, „the new electronic media“and multimedia services. The results of the experiment showed that the introduction of media education subject is justified. Students in the experimental groups compared with control groups achieved in tests and questionnaire surveys usually better results. Based on the results of the experimental verification project, media education was included in the list of compulsory and optional subjects for the 5th to 9th classes of primary school and the 1st to 4th classes of eight-year grammar schools since the school year 2008/2009 [24] .

The project indicates that children/students in the frame of media education in primary schools should better know and understand the rules of „media world" functioning and learn how to orient in it in a meaningful way. The main objective is to encourage reflection of children/students to media content and increase their sensitivity to use of specific content (e.g. inadequate incidence of violence and sexuality, information and content not respecting human dignity, etc.), teach them to detect manipulation features in media, to discover positive life values and assess behaviour of heroes in audio-visual and television works. Also to analyse advertisements, to take evaluation and critical attitude to produced entertainment, to verify the truth and neutrality of information, to create media content actively, to review it, etc..

Media education has its place in the State educational program. Its aim is to teach students of primary level education to understand better the rules of functioning of the media world, and depending on their age to orient in it, being able to assess media messages. At the secondary level, the emphasis is on developing their ability to competent and responsible 
treatment of different types of media, communication technologies and their products. It is expected, however, that pupils acquire the ability to use media meaningfully and selectively, to know the rules of their functioning and based on the received information form their own opinion. As a crosscutting theme it is incorporated into the mandatory education program in kindergartens. "At present, media education is no longer a compulsory part of the education program in primary and secondary schools; it is integrated in the State curriculum as a cross-cutting theme and can be taught in individual subjects, or in a form of individual courses, or as a single optional subject" [19] [20].

Media education officially became part of the NEP (National Education Program) as late as in 2008. Following the basic documents of the European Union, the Council of Europe and UNESCO (The United Nations Educational, Scientific and Cultural Organization), it is defined as "practical training aimed to build media competence understood as a critical and distinctive attitude towards the media to educate emancipated citizens, able to make their own opinion on the basis of the information received" ( The National Education Program ISCED 1, 2011). It contributes to the personal and social development of pupils to obtain a basic level of media literacy. In public documents, it is designed as a transversal theme, whose primary aim is to open for pupils further perspectives of knowledge, creating attitudes to the substantive issues of the modern world to gain experience to be used in everyday life. The transversal theme goes across educational fields, integrates educational area contents, and creates scope to obtain a comprehensive view of the same issue. It participates in the creation and development of core competencies.

The meaning and relevance of media education in society is growing proportionally with the continuous development of information and communication technologies, opportunities for their use and access to them, and also the variety and quantity of media content offered. The concept of media education in the Slovak Republic emphasizes that "All skills are factors of personal development that form awareness, critical thinking, and the ability to solve problems. In the information society, media literacy is an essential skill for all population age groups, and is considered as one of the basic assumptions of active and full citizenship in order to eliminate the risk of social exclusion" (The Concept of Media Education in the Slovak Republic in the context of lifelong learning, 2009). In the last decade, experts of international institutions in connection with the media have been focused on skills, then in responsible, creative, and critical approach, selection, impact, and effectiveness. In the context concept of media education in the Slovak Republic, it perceives media education as "the lifetime, systematic, and focused process of obtaining media competences and upgrading media literacy, the main objective of which is to support the reliable use of the media and to develop critical attitudes in relation to media contents, with an emphasis on moral principles and humanism" (The Concept of Media Education in the Slovak Republic in the context of lifelong learning, 2009).

According to the National Education Program, the main objective of media education is to gain and develop media literacy, to acquire media competences, i.e., the ability to receive, evaluate, analyse, and communicate a wide range of media content ( The National Education Program ISCED 1, 2011). The secondary goal in the cognitive field is to develop knowledge of individual types of media, their function, development, social, economic, technological, and organizational aspects of their functioning; to obtain a basic orientation of the types, functions, and effects of the media on children recipients; to form their own opinion; to know types of media products and the process of their formation; to understand and critically assess the medially processed and displayed reality; to know media means of expression, the manner of arrangement of media products; to use the media and its products differentiated based on the quality performance of its functions (information, education, ethic, moral, and fun) and meeting their own needs. The psychomotor area is focused on the development of these skills: To use the media in the communication process actively; to create and produce their own media products; to operate technical equipment and control new media technologies; and to work with other media makers in the process of communication. In the affective area, which plays a more and more significant role in media education since it also deals with emotional and attitudinal components, the goals are: To cooperate with other media makers in the process of communication; to take a positive attitude to media products that provide positive value orientation for life; to choose them; to reject media content that resists ethical standards and produces a distorted view of values, harmful, threatening an individual's personal development; to try to use a responsible approach and eliminate the negative impact of the media on the individual; to be able to review their relationship to the media; to reflect their habits when using the media; to correct them; and to substitute their own media consumption with an alternative activity ( The National Education Program ISCED 1, 2011). 
5. 2. 1. National Education Program and Media Education in Primary School. Several published studies in Slovakia indicate that since 2008 media education has not moved significantly on from the declarative nature to the real school experience. As noted above, we have defined the National Education Program, which is a general framework, a kind of an indicative compass how to go further. However, what is significantly missing is a next upgrading and more detailed specification of the document on the level of basic schools, and its adaptation to local conditions and needs. It is just one of our reasons to reflect the content of primary learning in SEP (School Education Programs) in selected primary schools in the context of a transversal topic-media education ${ }^{1}$. The content analysis method is intended to measure the level of a transversal theme and the structure of its content in SEPs. At the same time, we are looking for an answer to the question how such contents are reflected in educational areas and specific subjects.

We note that media education incorporated into the National Education Program as a transversal theme is conceived more generally; the share of its presence in the total content is about 3\%. The analysis of School Education Programs show that transversal themes are an integral part of the educational area content: Language and Communication; Mathematics and Handling Information; Nature and Society; Arts and Culture; People and Values; Health and Movement; Man and the World of Work, with an emphasis on the links and relationships between educational areas.

The transversal theme media education is particularly integrated into the curriculum of Slovak language and literature (six thematic units) in the form of interactive exercises: phonetic aspects of the language and spelling (literary Slovak, correct pronunciation and writing); communication and composition (simple narrative, description in oral and writing (SMS - short messages, e-mail, advertisement, and advertising); and reading and literature (film, radio, television, drama, and fairy tale). Thus, it supports both acquiring the basic rules of communication, dialogue, and argumentation. However, it is incorporated in the folder reading and literature; surprisingly little or almost not at all is it represented in composition. In English language and literature, it appears not more than in one thematic

\footnotetext{
${ }^{1}$ Interdisciplinary based educational model development and their implementation to state curriculum. Project Ministry of Education, Science, Research and Sport SR KEGA 023UK-4/2012, Božena Šupšáková, chief project. PrimIntegra.sk-Web support of integrated primary education content. Project Ministry of Education, Science, Research and Sport SR KEGA 047UK4/2013, Šušáková co-author of the project.
}

unit representing, 6.25\%. Usually, the National Education Program formulates the general objectives in the education area of mathematics and handling information as follows: "To understand the rules of functioning of the media world, and to orient in it depending on their age, to be able to assess messages disseminated by the media, to find positives in favor of their personal and professional growth, to realize the negative media influences on their personality, and to develop the media competences of pupils ${ }^{2}$. We find out that mathematics is a subject consisting of four thematic units; the transversal theme does not appear in any thematic unit, though in this case one would expect that the teacher will use new media to learn mathematical operations. Informatics is an ideal subject for the implementation of media/multimedia. In the analysed SEPs, it is usually broken down into five thematic units, which is directly related to the media. We appreciate that the content standard includes the thematic unit Internet security. The educational field nature and society and two subjects-natural science and regional studies. The subject natural science is usually divided into 10 thematic units. The transversal theme is represented in only one thematic unit (usually human body), which in our opinion is insufficient, since just in this subject there is wide scope to search, review, select knowledge and information from the Internet, encyclopaedias, as well as to create computer presentations and present subject contents through the media, multimedia, etc.. Creators of SEP more accentuate innovative approaches in regional studies, the transversal theme is incorporated into five thematic units of the total seven thematic units. They focus more on interactive maps, the Internet, television, and interactive boards, etc.. The educational field man and values deal with the compulsory optional courses of religion and ethics, which is conducted more educationally, and thus, creates appropriate scope to develop personal communication competences, as well as media competences. It is usually represented in four or five thematic units: attitudes and skills in interpersonal relations; ethics in the media, the functioning and impact of media in society; and the Internet as a source of information and entertainment, which is evaluated very positively. Thematic units are designed so that through the transversal topic pupils learn to observe sensitively perceive and assess various media programs. At the same time, to be able to name and define the basic media types, differentiate and compare media (newspapers, magazines, radio, television, and the Internet), as well as their role in society (informative, educational,

2 Formulation of the objectives of the SEP (School Education Program) in our survey. 
and entertaining) and to learn to distinguish between "positive" and "negative" forms of expression in print and digital media. The educational field arts and culture are perceived primarily through fine arts and music. The transversal theme media education is part of several thematic units, mainly aimed at the development of psychomotor skills: compositional principles of two- and three- dimensional imaging, computer graphics, stimuli of photographs, film and video, and virtual galleries.

Working with video deserves greater attentioni.e., the ability to perceive, read, interpret, and critically evaluate artefacts of everyday art and media production. In music education, the presence of media education is significantly lower.

Based on the content analysis of SEP, we note that the educational content of primary education from the perspective of developing media literacy is in accordance with the National Education Program. The structure of the transversal theme content reflects the content standard, SEP (The National Education Program ISCED 1, 2011), which is reflected in the specific areas of learning areas and subjects, especially in the SL (Slovak Language and Literature), IN (Informatics), ET (Ethics), FT (Folk Traditions), less in Fine AE (Arts/Art Education), partly in Natural SC (Science), PE (Physical Education), and TE (Technical Education). Only in one school is the representation of transversal theme in natural science at the level similar to folk traditions (see Figure 3).

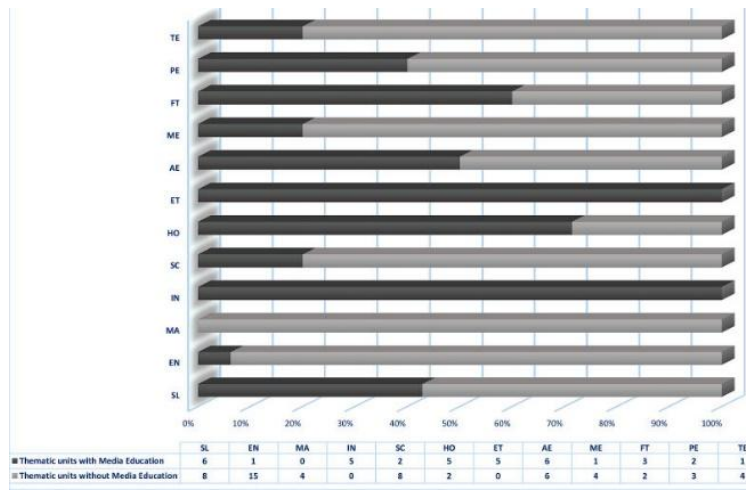

Figure 3. The share of media education in the thematic units by subjects.

Note. Subjects: SL (Slovak Language and Literature); EN (English); MA (Mathematics); IN (Informatics); Natural SC (Science); National HO (History); ET (Ethics), Fine AE (Arts/Art Education); ME (Music Education); FT (Folk Traditions), PE (Physical Education), TE (Technical Education).

Theoretically, the School Education Program reflects the present, the transversal theme amends the educational content of subjects, while creating scope for learning and developing attitudes on the substantive issues of the present, and obtaining new experience ${ }^{3}$. They are qualitatively developed quite well. It is a pity, however, that the school does not quantify its time allotment, and thus, does not guarantee with the quantity of integration of media education in learning areas and subjects. At the same time, there is an urgent requirement to develop common goals into each learning area, to specify them as far as possible in all subjects and grades, to name activities, and set outcomes of learning areas of individual subjects reasonably and clearly. We note that the content of SEP further emphasizes the development of media competences at the cognitive and psychomotor level. The analysis also shows that performance standards are related to media education only with some specified topics. It is necessary to develop appropriate evaluation tools of the transversal theme at the level of schools, classes, and pupils.

\section{Conclusion}

Although media education is part of the curriculum in many European countries, the Member States, its practical application is still problematic, even in relation with traditional media. Qualified teachers and educational materials are an essential condition of media education, and therefore the constant attention should be paid to teacher training in primary schools, as well as at other levels of education. Uncertainties remain in question, which place would media education have in the curriculum, what goals and tasks should be fulfilled. Also uncertainties remain in education methodology and assessment of results. "Most schools are still not adapted to the educational model, in which students and teachers are in a position of learning"[13]. This statement concerning deficiencies in media education throughout Europe unfortunately persists till today. Involved professionals, experts in media education identified misunderstanding and lack of status of the subject and its content in the educational system, incompetent teaching, inadequate teacher education, lack of basic educational facilities, lack of funds, etc.

We share the same opinion with recommendations of experts in media education [18] that are necessary several steps to improve the situation:

\footnotetext{
${ }^{3}$ Note: With the support of international projects, for example, the European Digital Library, Infovek, the national project use of ICT in subjects, Multimedia Reader, Internet Knowledge Olympic Games and other. These activities are usually a reflection of the quality and professional access of school teachers, their teamwork, and interest in education.
} 
- Initiatives and founding sources should be provided for national governments of Member States to exchange experiences with countries.

- Measurements tools should be introduced as integral parts of media education. It would particularly allow long term observations of trends, and would provide systematic measurements of skill levels and of cognitive critical thinking elements:

- Traditional media access/exposure

- Exposure to Internet and social networks

- Use skills (computer and Internet skills, and more sophisticated skills measurement for all media in educational systems)

- Protection skills: ability to change their privacy settings or to block other users online, from EU kids online content creation skills

- Content creation: making videos/taking photos on digital video, digital camera and mobile phones, SMS messages, post messages on Internet

- The manifestation of communicative abilities into media content is most characteristic among young populations. To extend the population that is active in these fields, secondary and tertiary education as well as lifelong learning initiatives targeting mature and elderly populations should promote the uptake of these elements of media literacy as key competences and skills and should promote the development of didactical tools, and extend teachers training programs of media teachers.

- The development of practical, ,easy-to-follow ${ }^{\text {ee }}$ educational tools or guidance sheets for media teachers.

This finding can be even more applied to the Slovak reality, where media education is only in the beginning. It is true that the legislative framework for media education and its anchoring in the system of formal and informal education in Slovakia we already have. Talking about basic education, in addition to the results of the experimental verification there are no relevant outcomes, even there is no known extent (and whether the education exists at all), and in particular, in what quality the education is performed, how teachers teach the subject, how many professionally trained teachers we actually have. It's a challenge for our applied research to evaluate the quality of school education programs just in this field and uncover possible deficiencies (Grant Ministry of Education, Science, Research and Sport SR, KEGA 023UK-4/2012). Now we cannot speak about a coordinated education system, where the activities of the state are linked with the activities of non-governmental and civil sectors. Minus is the lack of the Media Education Centre at the Ministry of Culture to be the coordinator of activities in the field of media education; it was to develop the concept of media education in non-formal education, plans and projects for the development of media education system. The commitment to establish it as part of the existing institutions at the Ministry of Culture failed because of austerity.

Today we have no other option, just keep doing what we started. Media education at primary and secondary levels of basic schools definitely deserves adequate attention because as a cross-cutting theme can enrich each pupil, but also teaching such subjects as mother language, history, geography, art. It is actually a good investment.

\section{References}

[1] Buckingham, D. (2000). The making of citizens: Young people, news and politics (pp. 221-223). London : Routledge.

[2] Hardt, H. (2004). Myths for the masses: An essay on mass commnication. Oxford: Blackwell Publishing Ltd..

[3] Hoechsmann, M., \& Poyntz, S. (2012). Media literacies: A critical introduction. Oxford: Blackwell Publishing Ltd..

[4] Interdisciplinary based educational model development and their implementation to state curriculum. Project Ministry of Education, Science, Research and Sport SR KEGA 023UK-4/2012, Božena Šupšáková, chief project.

[5] PrimIntegra.sk-Web support of integrated primary education content. Project Ministry of Education, Science, Research and Sport SR KEGA 047UK-4/2013, Šupšáková co-author of the project.

[6] Livingstone, S., Bober, M., \& Helsper, E. (2005). Internet literacy among children and young people: Findings from the UK children go online project. London: LSE Research Online. Retrived from http://eprints.lse.ac.uk/397/1/UKCGOonline Literacy.pdf

[7] Martens, H. (2010). Evaluating media literacy education: Concepts, theories and future directions. Journal of Media Literacy Education, 2, 1-22.

[8] McLuhan, M. (2008). A man, electronic media and culture (p. 262). Brno: Jota.

[9] Ofcom. (2008). Media literacy audit: Report on UK adults' media literacy. London: Ofcom.

[10] O’Neill, B., \& Hagen, I. (2009). Media literacy. In S. Livingston, \& L. Haddon (Eds.), Opportunities and risks for children (pp. 229-240). Bristol: The Policy Press.

[11] Potter, W. J. (2012). Media literacy. London: SAGE Publishing. 
[12] Project Zodpovedne.sk. (2008). Child safety in the use of Internet and mobile phone. Retrieved from http://www.zodpovedne.sk

[13] Recommendation of Commision No. 1466/2000. (2000). Media education. Council of Europe, The Parliamentary Assembly. Retrieved from http://www.culture.gov.sk/extdoc/2636/

[14] Recommendation of Commision No. 6464/2009. (2009). Commission recommendation on media literacy in the digital environment for a more competitive audiovisual and content industry and an inclusive knowledge society, Brussels. Retrieved, August 20, 2009, from http://ec.europa.eu/culture/media/literacy/docs/recom/c_20 09_6464_sk.pdf

[15] Roberts, D. F., \& Foehr, U. G. (2008). Trends in media use. The Future of Children, 18(1), 11-37.

[16] Šupšaková, B. (2012). Technological changeover to the internet age and its effect to social communication of the youth. ICT Education design : Processes, materials, resources 1 ( pp. 133-153). Zielona Gora: Universytet Zlielonogórski.

[17] Šupšáková, B. (2010). Reflection of the media in expressing the image of children and youth. In J. Masek, Z. Sloboda, \& V. Zikmund (Eds.), Media education in theory and practice pilsen (pp. 138-147). Pilsen: Faculty of Education, University of West Bohemia.

[18] Testing and Refining Criteria to Assess Media Literacy Levels in Europe. (2011). European Association for Viewers' Interests \& Danish Technological Institute, Final Report, p. 14.

[19] The National Education Program ISCED 0. (2008) Retrieved from http://www.statpedu.sk/files/documents/svp/ms/isced_0.pdf

[20] The National Education Program ISCED 1. (2008) Retrieved from http://www.statpedu.sk/files/documents/svp/1stzs/isced1/is ced1_spu_uprava.pdf

[21] The National Education Program ISCED 1. (2011) Media education (cross-cutting theme) (p. 2). Retrieved from

http://www.statpedu.sk/files/documents/svp/prierezove_te my/medialna_isced1.pdf

[22] The National Education Program ISCED 2. (2008) Retrieved from http://www.statpedu.sk/files/documents/svp/2stzs/isced2/is ced2_spu_uprava.pdf

[23] The National Education Program ISCED 3A. (2008) Retrieved from http://www.statpedu.sk/files/documents/svp/gymnazia/isce d3_spu_uprava.pdf
[24] The Concept of Media Education in the Slovak Republic in the context of lifelong learning (p. 24). December 16, 2009. The Resolution of the Government of the Slovak Republic.http://old.culture.gov.sk/ uploads/9z/9U/9z9UuLgW-4Iwh72hQv9adw/ vlastny_material.pdf

[25] Thomas, E., \& Jolly, St. (2004). Media literacy: A national priority for a changing world. American Behavioral Scientis, 48(1), 18-29.

[26] Tomkova, J. (2012). Mediation of safer internet use (p. 3). The Survey Final Report, Research Institute for Child Psychology and Pathopsychology, Bratislava. 